\title{
Chapter 9 \\ Staying BRiTE in the Dutch Teacher Education Context
}

\author{
Marjon Fokkens-Bruinsma, Michelle M. Gemmink, and Els C. M. Van Rooij
}

\begin{abstract}
Preservice teachers face the complex challenge of balancing the requirements of teacher education programmes and schools and developing a professional identity as a teacher. Developing the knowledge and skills to manage working as a teacher is important to prevent emotional exhaustion during teacher education and later in the teaching career. Therefore, it is important to begin building resilience during the teacher education programme. Dutch policymakers and teacher educators recognize this need; however, there are currently no structural practices in teacher education programmes to help preservice teachers build resilience. Thus, introducing the BRiTE framework and modules could be a beneficial opportunity for Dutch teacher education. This chapter focuses on describing the Dutch teacher education context and teacher educators' perceptions of resilience. We also discuss how the BRiTE modules can be implemented in Dutch teacher education programmes.
\end{abstract}

Keywords Resilience $\cdot$ Preservice teachers $\cdot$ BRiTE $\cdot$ Dutch teacher education programmes $\cdot$ Implementation

\subsection{Introduction}

By sending you this email I want to express that I am not doing so well at the moment. Last week I was feeling ill, but mainly stressed out. I also noticed that I have been feeling down.

The original version of this chapter was revised: Error in link has been corrected as "http://www. entree-online.eu/". The correction to this chapter is available at https://doi.org/10.1007/978-98115-5963-1_19

M. Fokkens-Bruinsma ( $\triangleleft)$ · E. C. M. Van Rooij

University of Groningen, Groningen, The Netherlands

e-mail: marjon.bruinsma@ rug.nl

E. C. M. Van Rooij

e-mail: e.c.m.van.rooij@rug.nl

M. M. Gemmink

KPZ University of Applied Sciences, Zwolle, The Netherlands

e-mail: M.Gemmink@kpz.nl 
Since Christmas holidays, I noticed that the pressure from school and my field experience made me push myself to the limit. This made me dislike education, which made me feel bad, especially since I was very enthusiastic in the beginning.

This quote comes from one of our pre-service teachers (PSTs) who contacted the main author in February 2017. It illustrates the problem of well-being and its potentially detrimental consequences for teacher outcomes. It also underscores the importance of conducting more research on PSTs' well-being and resilience. Policymakers and teacher educators acknowledge the importance of undertaking more research and giving more attention to PSTs resilience and well-being. However, little is known about the prevalence of mental health problems among PSTs and the well-being and resilience of PSTs (Zimmerman et al. 2018). Even less is known about how to help PSTs become more resilient, and no structural measures have been taken in the Netherlands to build PSTs' resilience. For this reason, the BRiTE framework (see Chap. 3) and related modules could be valuable for Dutch teacher education.

The main goal of this chapter is to provide more insight into the process of developing and adapting the BRiTE modules to a different international context. In particular, we focus on Dutch PSTs' well-being, a description of the Dutch teacher education context, Dutch teacher educators' perspectives of resilience, and our first experiences with the BRiTE modules. In this chapter, we discuss the problem of wellbeing and resilience among PSTs, followed by a short description of our research project. We then describe the Dutch teacher education context, including the education system, and compare the institutes involved in the project. In Sect. 3, we discuss teacher educators' views and current practices that enhance resilience. Sections 4 and 5 discuss how we plan on implementing the BRiTE modules in our context and offer recommendations to others who want to adapt the modules to their contexts.

\subsubsection{Dutch PSTs' Mental Health and Well-Being}

Higher education students experience challenges that might worsen their well-being and can even result in attrition (Baik et al. 2017; Fernandez et al. 2016). Furthermore, many higher education students in the Netherlands experience problems related to their well-being (Dopmeijer 2016). For example, Statistics Netherlands (2018) reported in its National Health Survey that $11 \%$ of 18 to 24 year olds reported poor mental health, and the Dutch Student Union (LSVB, 2017) reported that $75 \%$ of students were emotionally exhausted.

The problem might be even worse for PSTs because they face three distinct challenges. First, the teaching profession is complex, is emotionally demanding (Day et al. 2011), and can be considered 'emotional labour' (Hochschild 1983). This implies that teachers experience tension because the core of teaching involves continuous interactions between teachers and students and teachers are expected to regulate their emotions during these interactions. As Day et al. (2011, p. 27) state, "It is the ongoing demands on their intellectual energy, competence and capacity to connect 
self and subject and students that distinguishes the teaching self from the selves of other professionals". PSTs need to learn how to deal with these tensions, emotions and demands. Second, they must develop a professional identity as a teacher, which might evoke different tensions (Pillen et al. 2013) but might also be positively related to the development of resilience (Pearce and Morrison 2011). Third, PSTs' professional development takes place in at least two learning environments simultaneously: courses at a teacher education institute and field experience at a school. These environments have different cultures and different expectations of PSTs' learning goals (Leeferink et al. 2015). PSTs must learn to balance the requirements from both environments.

However, the exact number of PSTs experiencing mental health and well-being problems is relatively unknown, which makes research into these aspects important. Furthermore, Den Brok et al. (2017) found that attrition among new Dutch teachers is close to $15 \%$. They also found that attrition was lower for qualified teachers than unqualified teachers ${ }^{1}$ and suggested that teacher education can play a vital role in reducing stress and attrition. Turner and Braine (2016) also suggested that knowledge and skills on managing working life are important to prevent emotional exhaustion during teacher education and later in life.

So, how can we improve PSTs mental health and well-being? Building PSTs' resilience provides a valuable perspective. Research into teachers' resilience asks why certain teachers, despite the challenges of the profession, remain in the profession and how well-being, in terms of flourishing, flow and thriving, can be enhanced (Beltman et al. 2011; Mansfield et al. 2012). However, research on resilience is rather scarce in the Netherlands. It would, therefore, be worthwhile for the Dutch teacher education context to obtain more insight into PSTs' resilience and determine how teacher educators can build resilience.

\subsubsection{Project 'Life Is Tough but so Are You'}

Given the need to train more resilient PSTs and a general interest in the topic of resilience and well-being, a group of Dutch researchers and teachers of four teacher education institutes (Katholieke Pabo Zwolle [KPZ], Leiden University [LU], Utrecht University [UU], and the University of Groningen [UG]) are collaborating on the project Life is tough but so are you: Enhancing preservice teachers' resilience (LITBSAY) in May 2019. The main goal of this project is to gain more insight into Dutch PSTs' resilience and how teacher educators can help PSTs build resilience. Ethical approval for the project was obtained through the ethical committee of the Department of Teacher Education at UG.

\footnotetext{
${ }^{1}$ In the Netherlands, because of a shortage of qualified teachers, both schools for primary and secondary education can appoint unqualified teachers to classrooms on a temporary basis.
} 
For this project, we define mental well-being as a multidimensional concept that involves a subjective component (i.e. feelings of pleasure, life satisfaction or satisfaction of the basic needs for autonomy, competence and relatedness) and an objective component (i.e. blossoming, flourishing and living a 'meaningful' life) (Ryan and Deci 2000). We assume that mental well-being as a teacher outcome can be enhanced by teaching PSTs strategies to become resilient.

To gain more understanding on the concept of resilience, we took the BRiTE framework developed by Mansfield et al. (2016) as a starting point and used the findings from the ENhancing Teacher REsilience project in Europe (ENTREE). ${ }^{2}$ The ENTREE project defines resilience as "the process of, capacity for and outcome of positive adaptation as well as ongoing professional commitment and growth in the face of challenging circumstances". 3 These researchers conceive of resilience as a dynamic interplay of individual, situational and contextual characteristics that can be both risk and protective factors. Resilient teachers, therefore, not only bounce back after challenging or adverse situations but also thrive professionally and personally, resulting in job satisfaction, positive self-beliefs, well-being and commitment to the profession. In line with the review study of Mansfield et al. (2016) on factors that enhance resilience in teachers, we measure resilience in terms of the following factors:

- Personal resources, such as motivation and efficacy;

- Contextual resources, such as support from colleagues;

- Strategies, such as problem-solving;

- Professional outcomes, such as well-being and job satisfaction; and

- Academic outcomes, such as persistence and achievement in teacher education.

We formulated three aims and research questions (Fig. 9.1). First, we aim to identify PSTs' resilience during teacher education. Our focus here is to identify where, when and how resilience development takes place. Our research questions are, "How do PSTs experience resilience in terms of personal resources, contextual resources, strategies and outcomes?" and "What strategies can PSTs use to enhance their own resilience?"

Second, having identified PSTs' resilience and the activities they undertake to enhance their resilience, we evaluate what institutes and schools do to enhance PSTs' resilience. Therefore, our second goal is to identify practices in teacher education programmes and schools that help PSTs develop resilience. These practices might be, for example, a specific course dedicated to enhancing resilience, information about enhancing resilience or informal conversations about resilience in institutes and schools. The main research question related to this part of the project is, "What strategies do teacher education institutes and schools use to support PSTs' resilience?"

\footnotetext{
${ }^{2}$ More information on this project is available at http://www.entree-online.eu/.

${ }^{3}$ The theoretical framework concept paper is available on the project website at http://www.entreeonline.eu/.
} 


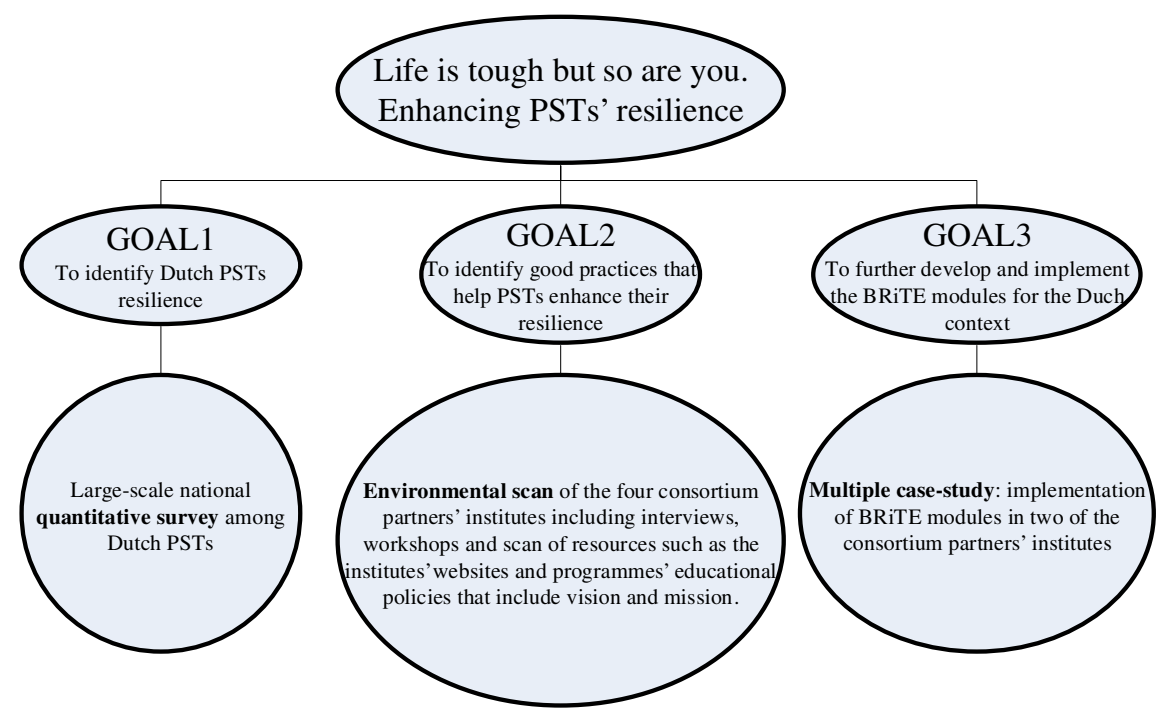

Fig. 9.1 Project goals and related data collection

Third, using the information gathered in these first parts of the project, we aim to adapt the BRiTE modules to the Dutch context to enhance PSTs' resilience during teacher education. We plan to implement the modules in two teacher education institutes, the KPZ and UG, where both PSTs and educators from the institutes and schools will be involved in small academic learning communities. The modules will be based on the BRiTE framework and the existing online modules. Our research questions during this stage focus on PSTs and teacher educators by asking the following: "How does a learning module focused on resilience affect preservice teacher personal resources, contextual resources, strategies and outcomes?" and "How does a learning module focused on resilience help teacher educators build resilience in preservice teachers?"

\subsection{The Dutch Teacher Education Context}

\subsubsection{Dutch Education System and Teacher Education}

The three goals to enhance ${ }^{4}$ PSTs' resilience are identified for both university-based teacher education programmes and professional teacher education programmes. In

\footnotetext{
${ }^{4}$ The two examples are based on general descriptions of the Dutch Teacher Education Context (https://www.rijksoverheid.nl/onderwerpen/hoger-onderwijs and https://www.nuffic.nl/ onderwerpen/hoger-onderwijs/).
} 
this chapter, we explain the structure of the Dutch education system and teacher education.

In the Netherlands, children enter primary education at the age of four. After primary education, at the age of 11 or 12 , students enter secondary education, which is ability-tracked. The lowest level is called vocational education, the intermediate level is called general secondary education and the highest level is called pre-university education. There are many different types of teacher education programmes following the different tracks and levels in the education system that focus on training teachers in primary or secondary education. In our study, two types of teacher education programmes are involved (Table 9.1). The first is a teacher education programme for primary school teachers, which is a four-year undergraduate bachelor's programme taught at universities of applied sciences. The second type of programme is a teacher education programme at the master's level offered at research-based universities. Completing such a programme leads to a qualification to teach a certain subject in all years of general secondary education and pre-university education. A master's degree in teaching can be obtained in two ways: (1) through a one-year postmaster's programme in teacher education (i.e. Post-Master Teacher Education) for PSTs who have already obtained a master's degree in a specific subject domain (e.g. English Language and Culture, Science) and (2) through an Educational Master programme, which consists of subject domain courses in the first year and teacher education in the second year, including a school-based field experience.

\subsubsection{The Two Contexts Involved}

The Katholieke Pabo Zwolle University of Applied Science is a small university of applied sciences that offers teacher education for future primary school teachers. The KPZ emphasizes interpersonal relationships between PSTs and lecturers and among PSTs. PSTs are assigned a tutor (teacher educator) who meets with them weekly in groups, varying from 25 PSTs in the lower years to a maximum of 10 in the upper year, to discuss the development of professional identity and provide support and advice. PSTs have field experiences during all four years of the programme. In the first three years, they spend one day per week in the school in addition to a whole week four times per year. In the fourth year of the programme, PSTs are assigned to a workplace and are responsible for their own classes for two days per week.

Research-based universities, such as Utrecht University (UU), Leiden University (LU), and University of Groningen (UG) have a one-year, Post-Master Teacher Education programme with an inflow of approximately 30 to 40 PSTs each year. In addition, they offer a two-year Educational Master with an inflow of approximately 80 to 130 PSTs each year. In both programmes, PSTs have school-based field experiences during the whole year in which they spend two to three days a week in the schools (usually with a requirement to teach four to eight lessons). In total, these PSTs teach for 140 hours. The master programmes start with foundation courses in 


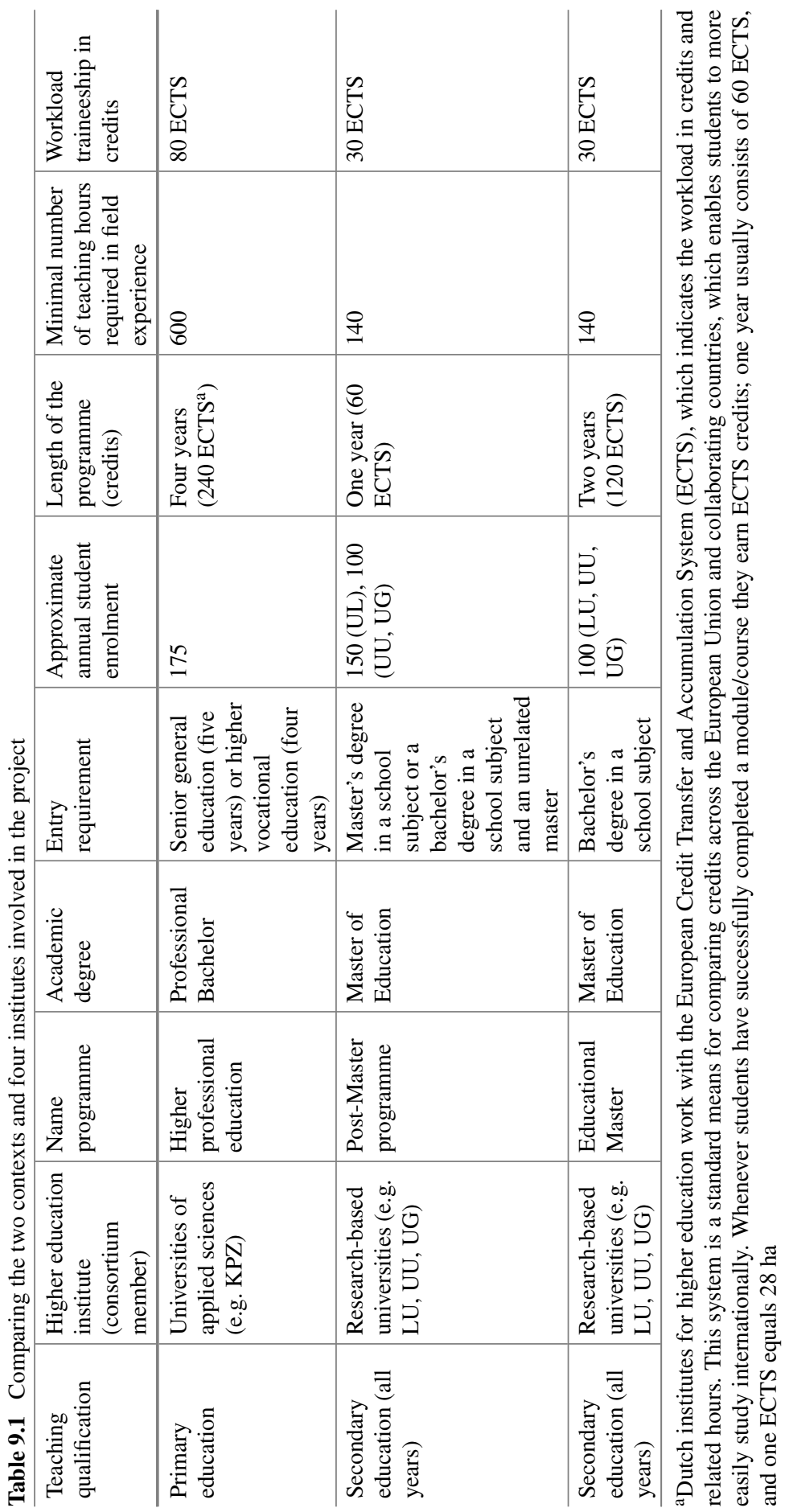


pedagogy, pedagogical content knowledge and didactics, followed by more in-depth courses.

\subsection{Teacher Educators' Views on Enhancing Resilience}

As a starting point for the second goal, which is to identify practices on how institutes and schools help PSTs enhance resilience, we carried out a small-scale environmental scan. The goals of this scan were:

1. To obtain an overview of current resilience-enhancing practices in Dutch teacher education;

2. To gain insight into teacher educators' views on resilience; and

3. To identify issues in relation to implementing resilience-enhancing practices in teacher education programmes.

We focused on four key themes of the BRiTE framework (Mansfield et al. 2016) that are important to consider in building PSTs' resilience during teacher education: relationships, well-being, taking initiative and emotions. Awareness of the importance of resilience and building resilience underpins these four themes as a fifth theme.

During a workshop for teacher educators at the UG, the BRiTE framework and its specific themes were briefly introduced. We developed a form to describe the different BRiTE themes, including a brief description of what these themes entailed. Using this form, we asked 15 teacher educators to indicate where in the programme they addressed these topics, to give examples of good practices and whether they felt they needed more professional development on a given theme. Next, we discussed their answers with the group. Of the 15 teacher educators, one did not give permission to use answers and three were researchers who did not have an active role in teaching or coaching PSTs. Next, we summarize the 11 remaining teacher educators' views and practices regarding building resilience in teacher education.

\subsubsection{Views on BRiTE Dimensions}

\subsubsection{Building Resilience}

Most teacher educators indicated that they talked to their PSTs about resilience and why resilience matters. However, when prompted to describe how they do this, teacher educators rarely used the term 'resilience'. Instead, they talked about '(physically and mentally) taking care of oneself', 'keeping all balls in the air', 'dealing with receiving feedback', 'time management', 'setting realistic goals' and 'learning to say "no"". Furthermore, addressing the topic of resilience did not happen structurally or in a pre-planned manner, but mostly in a reactive way, as a response to 
issues PSTs brought in. The majority of teacher educators described talking about building resilience when necessary during personal coaching sessions or in informal talks with PSTs and during a pedagogics or didactics course if the topic came up, such as when PSTs brought in a problem they were experiencing that touched on the topic of their well-being.

\subsubsection{Relationships}

Regarding relationships, all teacher educators indicated that at some point and in some way, they talked about the importance of building relationships as a (preservice) teacher. They did this both during courses and during one-to-one talks with PSTs. Teacher educators' emphasis when talking to their PSTs about relationships was on the important role of colleagues and fellow PSTs as a support system. Furthermore, almost half the teacher educators offered their PSTs strategies that would help them build relationships at the school where they were doing their school-based field experience. These strategies were mainly tips and tricks about how to introduce themselves, how to get to know their colleagues and how to gain the most from their colleagues' expertise.

\subsubsection{Well-Being}

All teacher educators discussed well-being topics with their PSTs, and the majority also offered specific strategies on how to take care of their mental health. As with the relationships theme, well-being was a theme that arose every now and then during courses and during individual coaching. Well-being strategies that many teacher educators advised their PSTs included setting realistic goals for themselves, protecting their boundaries, sharing success experiences, planning 'fun' activities and taking time for self-care.

\subsubsection{Taking Initiative}

As part of the 'taking initiative' theme, focusing on problem-solving and communication was common among the teacher educators. Problem-solving was mainly discussed during individual coaching and group coaching sessions, in which each PST brought in a case from his or her practicum experience. In general, teacher educators pressed their PSTs to talk about their challenges, not only with them, but also with teachers at the school where they did their field experience and with fellow PSTs. Regarding communication, teacher educators mainly referred to the course 'Communication in the classroom', which is a mandatory course within the teacher education programme at the UG. This course, however, focuses on communicating (verbally and nonverbally) with students, not with fellow teachers and other significant people in the PSTs' environment. Ongoing professional development is also a 
topic within the 'taking initiative' theme, but there were hardly any teacher educators who paid explicit attention to this; two indicated that during their course they mentioned how PSTs could keep learning after graduation.

\subsubsection{Emotions}

Teacher educators also addressed the theme of 'emotions', again mainly in an implicit and reactive way, both during courses and individual coaching. Many teacher educators contributed to their PSTs' optimism by focusing on positive things (e.g. what the PST is already good at) and by emphasizing the importance of putting experiences in perspective. Regarding the role of teachers' emotions during teaching, teacher educators paid attention to the importance of being aware of their own emotions as a teacher and not taking negative pupil behaviour personally.

\subsubsection{Summarizing Teachers' Perceptions of Resilience Building in the Programme}

This brief exploration of teacher educators' current practices confirms that many teacher educators talk about topics related to resilience and the four themes (i.e. relationships, wellbeing, taking initiative and emotions) and that the majority also offer their PSTs strategies (e.g. giving advice, providing 'tips and tricks') on building relationships in school, taking care of one's own mental health, dealing with problems and handling their emotions. However, it is also clear that teacher educators do these things in a rather ad hoc manner, that is, mainly in response to topics, cases or problems their PSTs bring in and not in a systematic, planned way. Nonetheless, most teacher educators felt that building resilience was important, as all could mention many examples of former or current PSTs who were struggling and could benefit from developing resilience.

An important issue mentioned by multiple teacher educators with regard to implementing resilience-enhancing practices in the teacher education programme was that the programme is already full and demanding and that there is no space for extra topics, such as resilience, to be included. A second problem that teacher educators mentioned is that they, too, lacked knowledge about resilience and resilience-building strategies. Finally, because the workshop in which we collected the views and practices of teacher educators on building resilience was voluntary, the sample might have been biased towards a group of teacher educators who are already working on supporting PSTs to become resilient teachers. 


\subsection{BRiTE Modules in Dutch Teacher Education Programmes}

\subsubsection{BRiTE and LITBSAY}

The main goal of the LITBSAY project is to gain more insight into PSTs' resilience and how teacher educators can help PSTs build resilience. In the first two parts of the project, we focus on identifying PSTs' resilience and the activities they undertake to enhance resilience. In the final part of the project, we adapt the BRiTE modules to the Dutch context as a tool to enhance PSTs' resilience. Tools for enhancing PSTs' resilience are uncommon in Dutch teacher education programmes, and there are no instructional methods that enable teacher educators to incorporate resilience building in their courses or programmes. Therefore, using a learning module based on the BRiTE modules is an important step. Our study used a blended learning module (e.g. Alammary et al. 2014). Building such a module for Dutch teacher education programmes includes developing an online environment, translating the BRiTE modules, testing and piloting the online environment with teachers and PSTs, and instructing the teacher educators involved in the implementation of the modules. These activities are included in the LITBSAY project planned from September 2019 to April 2022.

We plan on implementing the modules in two teacher education institutes, the KPZ and the UG, where both PSTs and educators from the institutes and schools are involved in learning communities. ${ }^{5}$ At the KPZ, the online modules will be implemented in the fourth year of the curriculum when PSTs are instructed in small groups supervised by a tutor. The blended learning module is implemented in two or three tutor groups and consists of 10 sessions. In each session, topics of the BRiTE modules will be discussed. At the university-based programme for teacher education, one or two small learning communities will be created in which PSTs, teacher educators from the institute and teacher educators from the school are invited to participate in five blended learning sessions. Each session will discuss the topics of the BRiTE modules. Because one of the goals of the study is to help teacher educators support their PSTs, the information will also be provided to teacher educators (in the institute and the schools) who are not involved in the implementation.

\subsubsection{BRiTE Modules: First Impressions and Suggestions}

The BRiTE modules offer a promising intervention to adapt to the Dutch teacher education context. As part of the project, we examined how best to adapt the modules. We decided to focus on two aspects: the development and design of the module and the implementation of the module. In the overall project, we included an advisory

${ }^{5}$ Le Cornu and Ewing (2008) suggested that learning communities can help PSTs develop resilience. 
role for members of the BRiTE team (Caroline Mansfield and Susan Beltman) to discuss these aspects. Building on discussions with the developers, the data from the teacher educators, the exploration of the BRiTE modules, the conversations with our advisory board and the BRiTE project leaders, we recommend that the following topics be considered when adapting and implementing the modules to a different context.

\subsubsection{Development and Design of the Modules}

\section{Content}

The BRiTE modules enable participants to obtain a great amount of knowledge on resilience and related strategies. All information and materials are grounded in the literature and in practice. Some of the sections on "what the experts say" might be difficult for younger PSTs in terms of language or familiarity with academic writing. This implies that these sections may need some adaptations. Furthermore, to make the modules more suitable for younger PSTs, it might be valuable to write the modules in a less formal language. It would also be helpful to be more explicit about why it is important to include perspectives from experts. The section on Emotions tends to focus on positive emotions, which is desirable and follows literature on positive psychology. An important addition, in our view, would be to note explicitly that it is also natural to have negative emotions and that these emotions can be both beneficial and detrimental to functioning. The BRiTE modules end with a reflection. We hope to determine whether adding a reflection or feedback moment after finishing each of the sections would be beneficial. The self-quizzes were functional; they organized ideas, cognitions and beliefs in advance. Some of the self-quizzes might be perceived as rather long and somewhat repetitive. It would be helpful to spread out these questions to keep them manageable.

\section{Conditions: GDPR, Collaboration, Costs}

When considering implementing the BRiTE modules in a different context, we believe, from our first explorations, that it is important to discuss issues related to the content of the learning modules, the design of the learning modules, the ethical issues surrounding working with the modules and the related costs. We recommend adding these issues in a license of agreement.

\section{Native Language}

For our study, we considered it important to translate the modules to the Dutch language, especially because we are working with younger age groups. In addition, mental health, well-being and resilience can be sensitive topics that might raise emotions. As such, working with the modules in one's native language decreases the cognitive load (Roussel et al. 2017). Relatedly, it is important to focus on the content of the modules and their suitability for different groups. 


\section{Teaching Standards}

Section 3.1.4 on taking initiative uses Australian standards. It is imperative to connect the modules with the Dutch teaching standards, ${ }^{6}$ which would also help stakeholders assess the importance of focusing on resilience and resilience strategies. Although the consortium members compared the Australian and Dutch teaching standards globally, more information is required on the key differences and similarities.

\subsubsection{Implementation of the Modules}

\section{Workload}

Another concern regards determining how to incorporate this blended learning module in teacher education programmes that already have a high workload. This is important from both PSTs' and teacher educators' perspectives. Both groups expressed concerns about the workload in our first discussion. Furthermore, studies have discussed the high workload of higher education staff (e.g. https://www.vsnu. nl/en_GB/workloads) and PSTs (e.g. Klassen et al. 2013).

\section{Stakeholders}

Before implementing the BRiTE modules, it is important to think about the people who need to be involved and how to keep them involved. We, therefore, discussed which stakeholders might be involved in our intervention and how to implement the BRiTE modules. During the process, we mainly talked to teacher educators and school leaders who were interested in and enthusiastic about enhancing resilience. We also talked to a few teacher educators who were less enthusiastic and had different beliefs about the question of addressing resilience in the teacher education programme. For our project, we decided to start with teacher educators who are interested in and enthusiastic about resilience in the hope that they would influence others during the course of our project.

\section{Types and Levels of Implementation}

One concern a student expressed after testing the modules was whether a person could obtain resilience strategies or become more resilient using only the online version of the module. The student recommended incorporating the modules in teacher education practice and supporting PSTs going through the module using the "Blended Learning" (dine-in or takeaway) or "Pick and Mix" (buffet) method, as described in the implementation guidelines. ${ }^{7}$ Thus, it is important to think about how to implement the BRiTE modules in a teacher education programme. Price et al. (2012) also discussed the implications for enhancing resilience within teacher education. They

\footnotetext{
${ }^{6}$ More information on Dutch teaching standards is available at https://zoek.officielebekendmak ingen.nl/stb-2017-148.html.

${ }^{7}$ https://www.brite.edu.au/Media/Default/Instructions/BRiTE\%20Implementation\%20Guideli nes\%202015.pdf.
} 
emphasized thinking carefully about the constructs of resilience and how they can be embedded in the programme. When thinking about a large-scale implementation of the programme, it might also be helpful to examine the literature related to curriculum change and changing beliefs to identify how best to implement it on a broader scale and how to convince stakeholders of the importance of doing so. Thus, the transfer to teacher education practice needs to be kept in mind, and different types and levels of implementation can be considered.

The types and levels of implementation also need to be considered in relation to PST and teacher educator workloads. Because PSTs mentioned that they find it challenging to balance the requirements of the teacher education programme and the school, it would be worthwhile to involve teachers in the schools who work closely together with PSTs during the implementation of the BRiTE modules (Blume et al. 2010).

\subsection{Conclusion}

Enhancing PSTs' well-being and resilience is beginning to gain more attention in Dutch policy and teacher education programmes. However, information on wellbeing and resilience, and methods of enhancing this in teacher education, is still uncommon. Therefore, raising awareness about these topics by implementing the BRiTE modules in Dutch teacher education is an important step forward. In this exploratory chapter, we elaborated on the process of developing and adapting the BRiTE modules to a different national context.

Having talked to 11 teacher educators about this topic, we found that most of them consciously or unconsciously pay attention to the themes and topics in the BRiTE framework, either in their courses or in individual sessions with PSTs. The teacher educators tended to offer PSTs strategies and provide tips and tricks, mainly in response to PSTs' questions, cases or problems. There was no structural attention to resilience and resilience strategies in the programme, though all teacher educators were aware of its importance.

Two concerns the teacher educators mentioned were that (a) the programme is already full, and extra topics might come at the cost of other topics, and (b) there is a general lack of knowledge among teacher educators on resilience and resiliencebuilding strategies. This implies that careful consideration of how to implement the blended learning module in the Dutch context and to professionalize teacher educators is important.

To conclude, the theoretical framework (Mansfield et al. 2016) and the BRiTE modules are promising tools to enhance Dutch PSTs' resilience. Increasing attention to enhancing PSTs' resilience is important, which is why it is encouraging that Dutch policymakers and teacher educators have begun acknowledging this topic. We are excited to work towards the goal of making PSTs more resilient and that, while doing so, we have the opportunity to work together with the BRiTE team to use the BRiTE modules in our teacher education programmes. 
Acknowledgements This research is part of the project 'Life is tough but so are you: Enhancing preservice teachers' resilience' (40.5.18650.036) funded by the Netherlands Initiative for Education Research (NRO). We also acknowledge the support of our other consortium members, including Monika Louws, Dineke Tigelaar, Ellen Jansen, Ietje Pauw and Martine van Rijswijk, and the BRiTE team members, Caroline Mansfield and Susan Beltman.

\section{References}

Alammary, A., Sheard, J., \& Carbone, A. (2014). Blended learning in higher education: Three different design approaches. Australasian Journal of Educational Technology, 30(4), 440-454. https://doi.org/10.14742/ajet.693.

Baik, C., Larcombe, W., Brooker, A., Wyn, J., Allen, L., Field, R., \& James, R. (2017). Enhancing student mental wellbeing. Melbourne Centre for the Study of Higher Education. Retrieved from http://melbourne-cshe.unimelb.edu.au/data/assets/pdf_file/0006/2408604/ MCSHE-Student-Wellbeing-Handbook-FINAL.pdf.

Beltman, S., Mansfield, C. F., \& Price, A. (2011). Thriving not just surviving: A review of research on teacher resilience. Educational Research Review, 6(3), 185-207. https://doi.org/10.1016/j.edu rev.2011.09.001.

Blume, B. J., Ford, K., Baldwin, T., \& Huang, J. (2010). Transfer of training: A meta-analytic review. Journal of Management, 36(4), 1065-1105. https://doi.org/10.1177/0149206309352880.

Day, C., Edwards, C., Griffiths, A., \& Gu, Q. (2011). Beyond survival: Teachers and resilience. Retrieved from http://www.nottingham.ac.uk/education.

Den Brok, P., Wubbels, T., \& Van Tartwijk, J. (2017). Exploring beginning teachers' attrition in the Netherlands. Teachers and Teaching: Theory and Practice, 23(8), 881-895. https://doi.org/ 10.1080/13540602.2017.1360859.

Dopmeijer, J. M. (2016).Factsheet mantelzorgende student Hogeschool Windesheim 2016. Retrieved from http://www.windesheim.nl/onderzoek/onderzoeksthemas/gezondheid-en-Wel zijn/verslavingspreventie/project-five.

Dutch Student Union. (2017). Van succes-student naar stress-student. Hoe groot is het probleem? [From being a successful student to being a stressful student. How big is the problem?] Utrecht: LSVB.

Fernandez, A., Howse, E., Rubio-Valera, M., Thorncraft, K., Noone, J., Luu, X., et al. (2016). Setting-based interventions to promote mental health at the university: a systematic review. International Journal Public Health, 61(7), 797-807. https://doi.org/10.1007/s00038-016-0846-4. Epub 2016 Jun 30.

Hochschild, A. R. (1983). The Managed Heart: Commercialization of Human Feelings. Berkeley, CA: University of California Press.

Klassen, R., Wilson, E., Siu, A. F. Y., Hannok, W., Wong, M. W., Wongsri, N., et al. (2013). Preservice teachers' work stress, self-efficacy, and occupational commitment in four countries. European Journal of Psychology of Education, 28, 1289-1309. https://doi.org/10.1007/s10212012-0166-x.

Le Cornu, R., \& Ewing, R. (2008). Reconceptualising professional experiences in pre-service teacher education... reconstructing the past to embrace the future. Teaching and Teacher Education, 24(7), 1799-1812. https://doi.org/10.1016/j.tate.2008.02.008.

Leeferink, H., Koopman, M., Beijaard, D., \& Ketelaar, E. (2015). Unraveling the complexity of student teachers' learning in and from the workplace. Journal of Teacher Education, 66(4), 334-348. https://doi.org/10.1177/0022487115592163.

Mansfield, C. F., Beltman, S., Price, A., \& McConney, A. (2012). "Don't sweat the small stuff': Understanding teacher resilience at the chalkface. Teaching and Teacher Education, 28, 357-367. https://doi.org/10.1016/j.tate.2011.11.001. 
Mansfield, C. F., Beltman, S., Broadley, T., \& Weatherby-Fell, N. (2016). Building resilience in teacher education: An evidenced informed framework. Teaching and Teacher Education, 54, 77-87. https://doi.org/10.1016/j.tate.2015.11.016.

Pearce, J., \& Morrison, C. (2011). Teacher identity and early career resilience: Exploring the links. Australian Journal of Teacher Education, 36(1), 48-59. https://doi.org/10.14221/ajte.2011v3 $6 n 1.4$.

Pillen, M. T., den Brok, P. J., \& Beijaard, D. (2013). Profiles and change in beginning teachers' professional identity tensions. Teaching and Teacher Education, 34, 87-93. https://doi.org/10. 1016/j.tate.2013.04.003.

Price, A., Mansfield, C. F., \& McConney, A. (2012). Considering 'teacher resilience' from critical discourse and labour process theory perspectives. British Journal of Sociology of Education, 33(1), 81-95. https://doi.org/10.1080/01425692.2011.614748.

Roussel, S., Roussel, S., Joulia, D., Tricot, A., \& Sweller, J. (2017). Learning subject content through a foreign language should not ignore human cognitive architecture: A cognitive load theory approach. Learning and Instruction, 52, 69-79. https://doi.org/10.1016/j.learninstruc. 2017.04.007.

Ryan, R. M., \& Deci, E. L. (2000). Self-determination theory and the facilitation of intrinsic motivation, social development, and well-being. American Psychologist, 55(1), 68-78. https://doi. org/10.1037/0003-066X.55.1.68.

Statistics Netherlands. (2018). One in 12 young people have poor mental health. Retrieved from https://www.cbs.nl/en-gb/artikelen/nieuws/2018/45/one-in-12-young-people-have-poormental-health.

Turner, S., \& Braine, M. (2016). Embedding wellbeing knowledge and practice into teacher education: Building emotional resilience. TEAN Journal, 8(1), 67-82.

Zimmermann, F., Rösler, L., Möller, J., \& Köller, O. (2018). How learning conditions and program structure predict burnout and satisfaction in teacher education. European Journal of Teacher Education, 41(3), 318-342. https://doi.org/10.1080/02619768.2018.1448778.

Open Access This chapter is licensed under the terms of the Creative Commons Attribution 4.0 International License (http://creativecommons.org/licenses/by/4.0/), which permits use, sharing, adaptation, distribution and reproduction in any medium or format, as long as you give appropriate credit to the original author(s) and the source, provide a link to the Creative Commons license and indicate if changes were made.

The images or other third party material in this chapter are included in the chapter's Creative Commons license, unless indicated otherwise in a credit line to the material. If material is not included in the chapter's Creative Commons license and your intended use is not permitted by statutory regulation or exceeds the permitted use, you will need to obtain permission directly from the copyright holder.

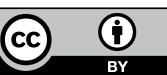

